\section{Birlesik Dünya Arastırma Global Journal of Computer$$
\text { BD-CENTER }
$$ \\ Innovasyon ve Yayıneılık Merkezi

\author{
Sciences: Theory and \\ Research
}

Volume 10, Issue 2, (2020) 27-47

$\underline{\text { www.gjcs.eu }}$

\title{
Social impact assessment process for industry 4.0 to achieve sustainable artificial intelligence systems
}

\author{
Vijayan Gurumurthy Iyer*, DEBM Counsellor, EDI of India, 382428, India
}

\section{Suggested Citation:}

Iyer, G. V. (2020). Social impact assessment process for industry 4.0 to achieve sustainable artificial intelligence systems. Global Journal of Computer Sciences: Theory and Research. 10(2), 27-47. https://doi.org/10.18844/gics.v10i2.5393

Received June 31, 2020; revised August 29, 2020; accepted October 01, 2020.

Selection and peer review under responsibility of Prof. Dr. Dogan Ibrahim, Near East University, Cyprus.

(C2020 Birlesik Dunya Yenilik Arastirma ve Yayincilik Merkezi. All rights reserved.

\begin{abstract}
The strategic environmental assessment (SEA) process can be broadly defined as a study of the social impacts of a proposed project, plan, policy or legislative action of intelligence systems on the society, environment and sustainability. The SEA process for sustainable intelligent systems has been aimed to incorporate society, environment and sustainability factors into the project planning and decision-making process for sustainable intelligent systems. Artificial intelligence systems (AIS) should consider the titled 'environmental impact assessment (EIA)' process that can be defined as the systematic identification and evaluation of the potential impacts (effects) of proposed projects, plans, programmes, policies or legislative actions relative to the biological physical, physico-chemical, biological, cultural, socio-economic and anthropological components of the total environment. The SEA process protocol is important as it has been proposed for studying and checking the productivity and quality of AIS. This treaty and official government procedures of SEA were helpful in the decision-making process much earlier than the EIA process.
\end{abstract}

Keywords: Artificial intelligence, business, economics, environment, industry.

* ADDRESS FOR CORRESPONDENCE: Vijayan Gurumurthy Iyer, DEBM Counsellor, EDI of India, 382428, India.

E-mail address: vijayaniyergurumurthy@rediffmail.com 
Iyer, G. V. (2020). Social impact assessment process for industry 4.0 to achieve sustainable artificial intelligence systems. Global Journal of Computer Sciences: Theory and Research. 10(2), 27-47. https://doi.org/10.18844/gjcs.v10i2.5393

\section{Introduction}

The legislation of the environmental impact assessment (EIA) process was established in 1970 by the enactment of the National Environmental Policy Act (NEPA) in the USA [1]. This was first time that the EIA process became an official tool in the construction sector to protect the environment. Three of the significant terms used while complying with the requirements of NEPA process are 'environmental inventory', 'environmental impact assessment process' and 'environment impact statement'. ElAs of design and construction of engineering structures were undertaken in order to protect the environment during the year 1950 in Japan, Europe and North America [2]. The purpose of the EIA process is to encourage the consideration of the environment in organisational planning and decisionmaking process. Historically, the choice of proposed projects, policies, plans, programmes, permits, procedures or legislations was primarily based on only one criterion called economic viability. Today, it is necessary to consider three criteria: economic, environmental and social viabilities. Environment coupled with sustainable intelligent systems is an intricate managerial approach that was the targeted research area to achieve socio-economic improvement and sustainability based on the triple bottom line approach (economical, environmental and social) and feasibility studies [3].

Product environmental life cycle analysis (LCA) has been studied and checked for identifying and measuring the impact of artificial intelligence (AI) systems on engineering industrial products on the environment and sustain efficacy by means of mass and energy balance methods [4]. LCA considers the activities related to raw materials, transformation, ancillary materials, equipment, method, market, manpower, production, use, disposal and ancillary equipment. As far as construction safety is concerned, personal protective equipment and materials (PPEMs) that include garments, clothing, gloves, safety shoes, hard hats, safety glasses, shields, respirators, full aprons, safety belts and other safety items have to be used by individuals. Such equipment is important for personal protection and for safety. It is the manager's and supervisor's responsibility to ensure that they are used. The enactment of worker's compensation law and occupational disease law shall increase materially the cost of insurance to the industry. The increased cost and the certainty with which it is applied will put a premium on accident prevention work. This cost can be materially reduced by the installation of safety devices. Advanced sustainable intelligent system research experience has shown that approximately $80 \%$ of all the accidents are preventable. EIA and environmental health impact assessment (EHIA) processes have been conducted for nuclear power plants to consider the safety and health impacts to mitigate psychological health loadings on workers and nearby residents. The strategic environmental assessment (SEA) system is a potentially useful element of good environmental and social management and sustainable development; however, as currently practiced in industries, it is far from perfection. Emphasis should be given in industries on maintaining economic viability of the operation, while in turn taking care to preserve the ecological and social sustainability of the country. The international EIA process, which has been studied, required a multidisciplinary approach duly conducted at a very early stage of the Indo-Matsushita Midget electrode project in 1982 at Tada for technical, economic, ecological and social sustainability.

The PPD process should include the integrated consideration of technical or engineering, economic, environmental, safety, health, social and sustainability factors to achieve intelligence excellence. Prior to the NEPA process in 1970 in the USA, technical and economic factors dominated the world's constructional projects. The objective of the study is to conceptualise the SEA process for intelligent systems based on 15 sustainable detailed project reports (DPRs) submitted by the extension learners of the Diploma in Entrepreneurship and Business Management (DEBM) course conducted by the Entrepreneurship Development Institute of India (EDI of India) during the research year (RY) 19992020 under the author's counsellorship. The design of the study is cross-sectional. 


\section{Materials and Methods}

The SEA process for sustainable intelligent systems is a predictable process and is devised into two phases [5]. The first phase is the initial environmental and sustainability evaluation (IESE) and the second phase is the environmental and sustainability impact studies (ESIS). IESE has been carried out for the Japanese Matsushita Carbon Company's proposed project, plan, programme, policy, permit, procedure and legislative action in India to determine whether potentially adverse effects on the environment and sustained efficacy with respect to the physical, chemical, biological, economical and socio-economic environment and on human health and well-being are significant or whether mitigation measures can be adopted to reduce or eliminate adverse environmental and sustainability impacts. The detailed SEA procedure can be called as ESIS, which was applied to identify and evaluate the environmental and sustainability consequences for both beneficial and adverse impacts in order to ensure that the environmental and sustainability impacts were taken into consideration in organisational planning and decision-making process. The SEA process for sustainable intelligent systems is designed to identify and predict the potential impacts of the physical, biological, ecological, socio-economic and cultural environment and on human health and well-being are adequately protected [6]. Given below are some of the methods and techniques applied for the sustainable project formulation and appraisal of 15 DEBM extension learners of the EDI of India attached with the professional counsellor and coordinator for the various projects, such as the midget electrode (battery carbon rod) project, nuclear power plant and construction project [5]:

1. Expert judgment and stakeholders' sentiments;

2. Checklist and matrices;

3. Multi-criteria analysis;

4. Case comparisons;

5. Simulation models;

6. Software and information system;

7. Questionnaires;

8. Group discussions;

9. Delphi approach;

10. Flow charts and decision trees;

11. Contingency analysis;

12. Overlays;

13. Fuzzy logics.

Environment and sustainability compliance requirements have been identified and evaluated systematically in these sustainable intelligent system projects (http://debmediiindia.ac.in/counsellors/student record). Fifteen DPRs of DEBM learners were formulated and appraised (http://www.ediindia.org/doc/list of institutions for website_latest.pdf.serial number68) (http://debm.ediindia.ac.in; Agency code: 80410, Password: 80410) [5].

\subsection{Stepwise structure of the SEA process}

The SEA process has been itemised according to the following nine steps:

1. Preliminary activities and decision of terms of references;

2. Scoping;

3. Study of base line data;

4. SEA and evaluation;

5. Evaluation of alternative measures;

6. Assessment of alternative measures;

7. Preparation of final documents; 
8. Decision-making;

9. Monitoring, measurement and control opportunities for resource transformation and project implementation and its SEA process.

\subsection{Conceptual framework for screening and scoping of the SEA process for sustainable intelligent systems}

The screening and scoping processes are the items which are employed in the SEA processes (Figure 1).

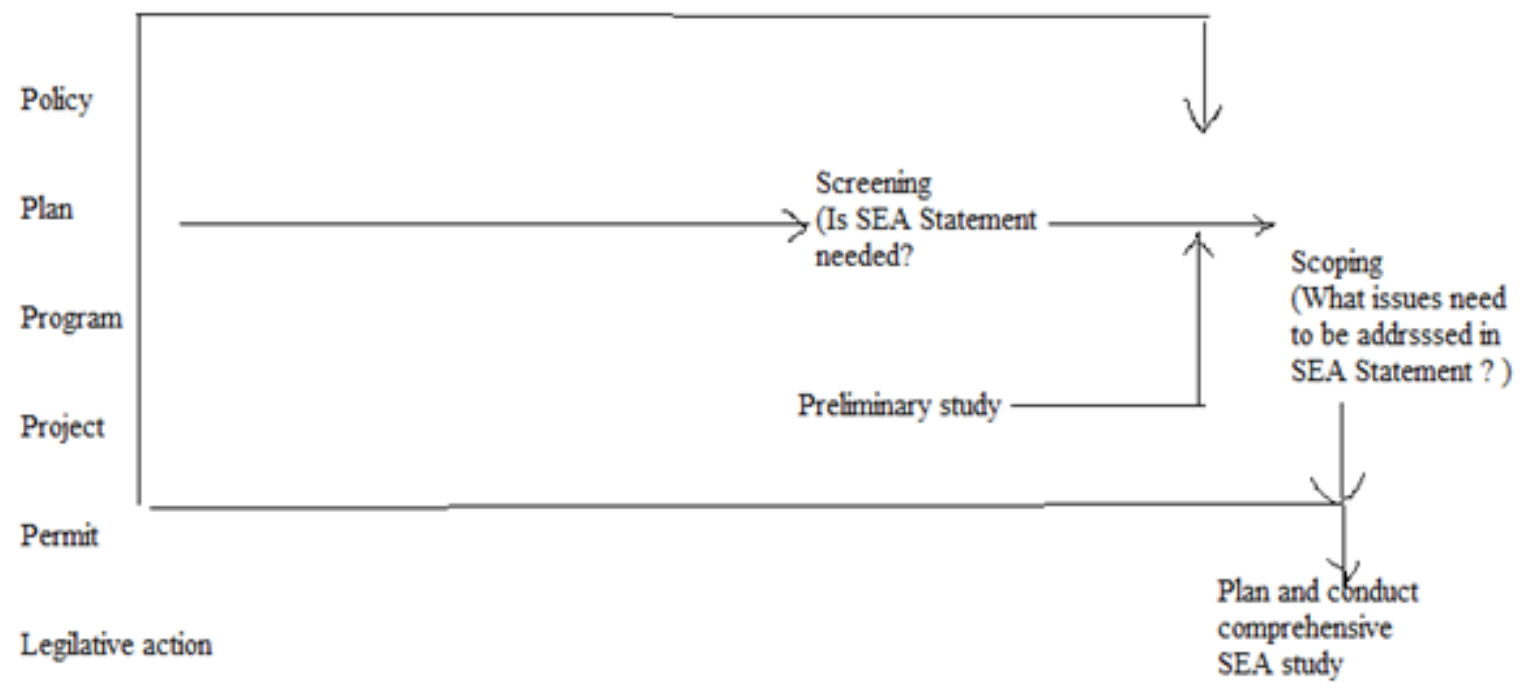

Figure 1. Conceptual framework for the screening and scoping processes of the SEA process

Strategic Environmental Assessment Process

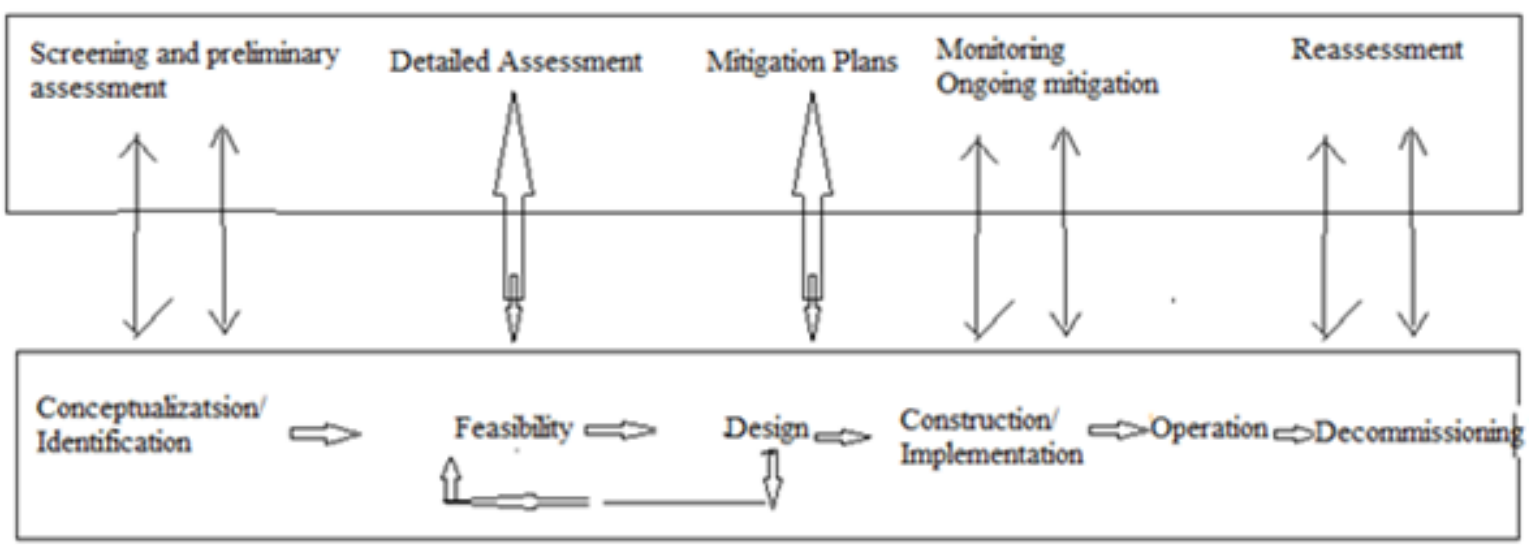

Project Life Cycle

Figure 2. SEA process at different phases of the life cycle assessment project

Three most significant items are 'strategic environmental assessment inventory, EIA and strategic EIA statement'. The PPD process should include the integrated consideration of technical, economic, environmental, social, safety, health and sustainability factors (Figure 2). 


\subsection{Strategic environmental assessment management plan (SEMP)}

A SEMP is a detailed plan and schedule for measures to minimise and mitigate any potential environmental and sustained efficacy impacts. SEMP should consist of a set of measurements, monitoring, control (mitigative) and institutional measures to be considered during the implementation and operation of the proposed projects to eliminate adverse environmental and sustainability impacts or offset them or reduce them to acceptable levels. The SEA process aims to incorporate environmental and sustainability considerations into strategic planning and decisionmaking processes of the project formulation and appraisal. International EIAs are important considerations in the project planning and decision-making process [7]. It has been imperative to consider international EIAs in concrete projects to mitigate the $\mathrm{CO}_{2}$-induced climate warming problem and the stratospheric ozone depletion problem. The international EIA process has a potentially good environmental management [2].

\section{Results and Discussion}

During the last two centuries, due to the fast urbanisation and industrialisation along with the advancement of science, engineering and technology, there have been considerable developments in the engineering sector with the resultant wastage of a copious amount of resources and tremendous environmental stress. Subsequently, it was realised that there were many adverse impacts on the environment and society. These unsustainable construction developments have sustained environmental growth [7]. It is required to apply sustainable intelligent systems for the sustainability of design and development, quality of life, safety on earth and continuous process improvement of our environment, which is of utmost importance. Sustainable development means a kind of development that should occur without damages to the environment. Hence, hectic developmental activities during the last two centuries have caused considerable environmental and social impacts. These impacts have been measured, monitored and mitigated by the international EIA process (Figure 3 ).

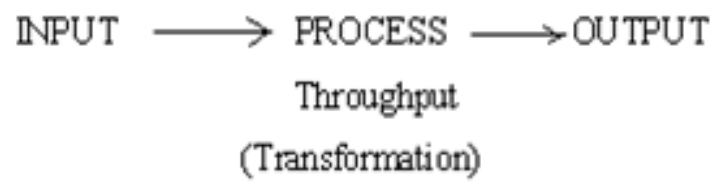

Figure 3. Process approach of Al systems for sustainable development

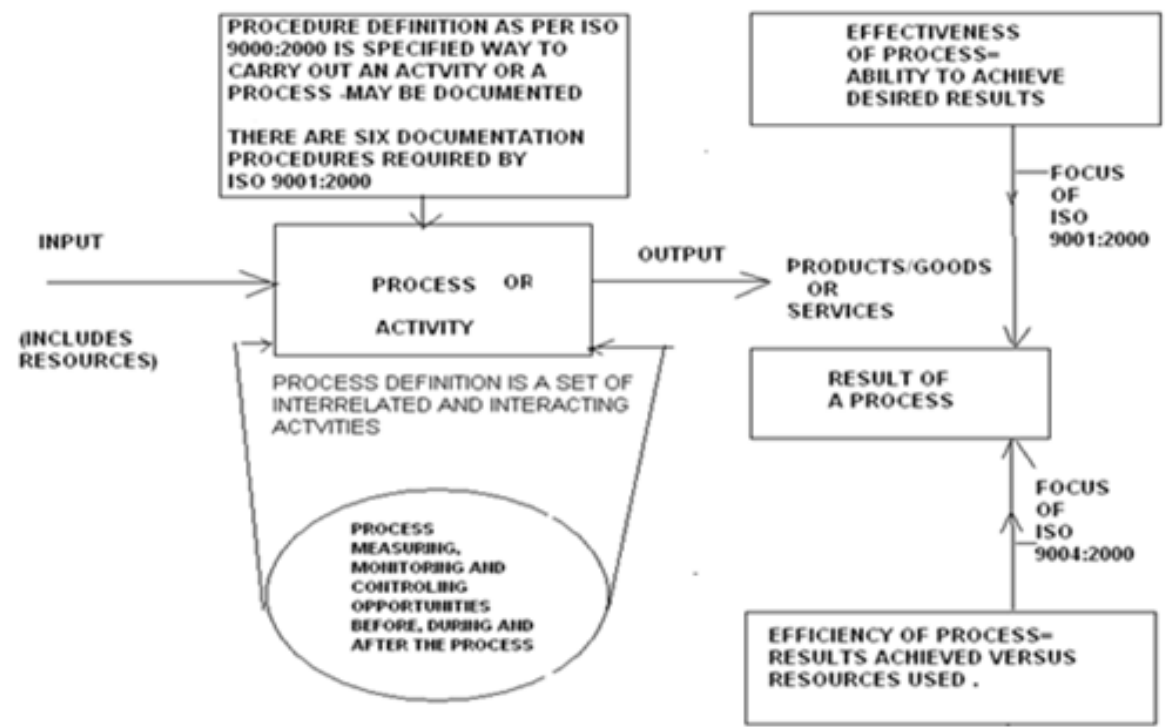

Figure 4. Schematic diagram of the sustainable Al systems 
International EIAs are important in the international project planning and decision-making process that mitigates potential environmental impacts in more than one country [7]. The use of sustainable intelligent and sustainable technology and management systems for the environment and sustainability is considered in two areas, i.e., sustainable development with global problems and prevention technologies that are designed to reduce the environmental effects of products and processes (Figure 4).

\section{ALL ENVIRONMENTAL AND SUSTAINABLITY IMPACTS}
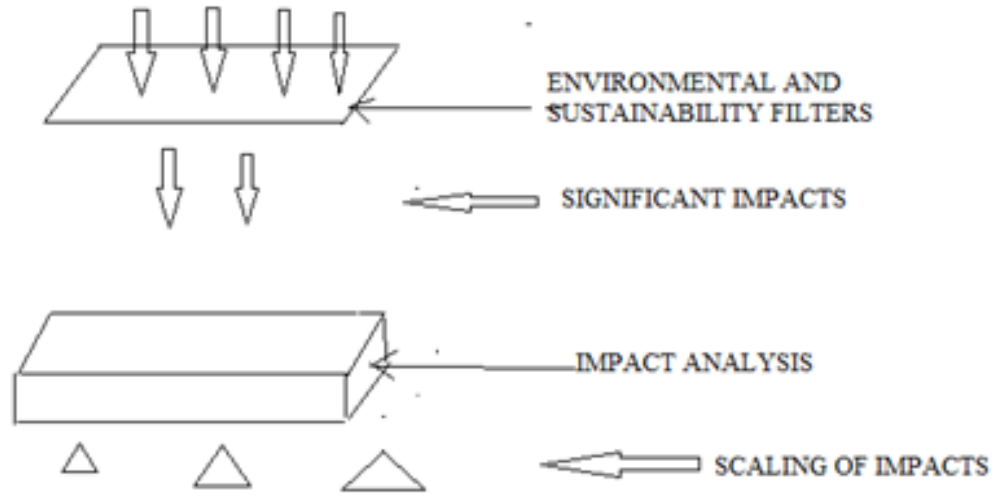

Figure 5. Procedure for finding out the significance of environmental and sustainability effects

The integration of environmental protection and economic development is the most important strategic social environmental assessment tool in achieving sustainable development (Figure 5).

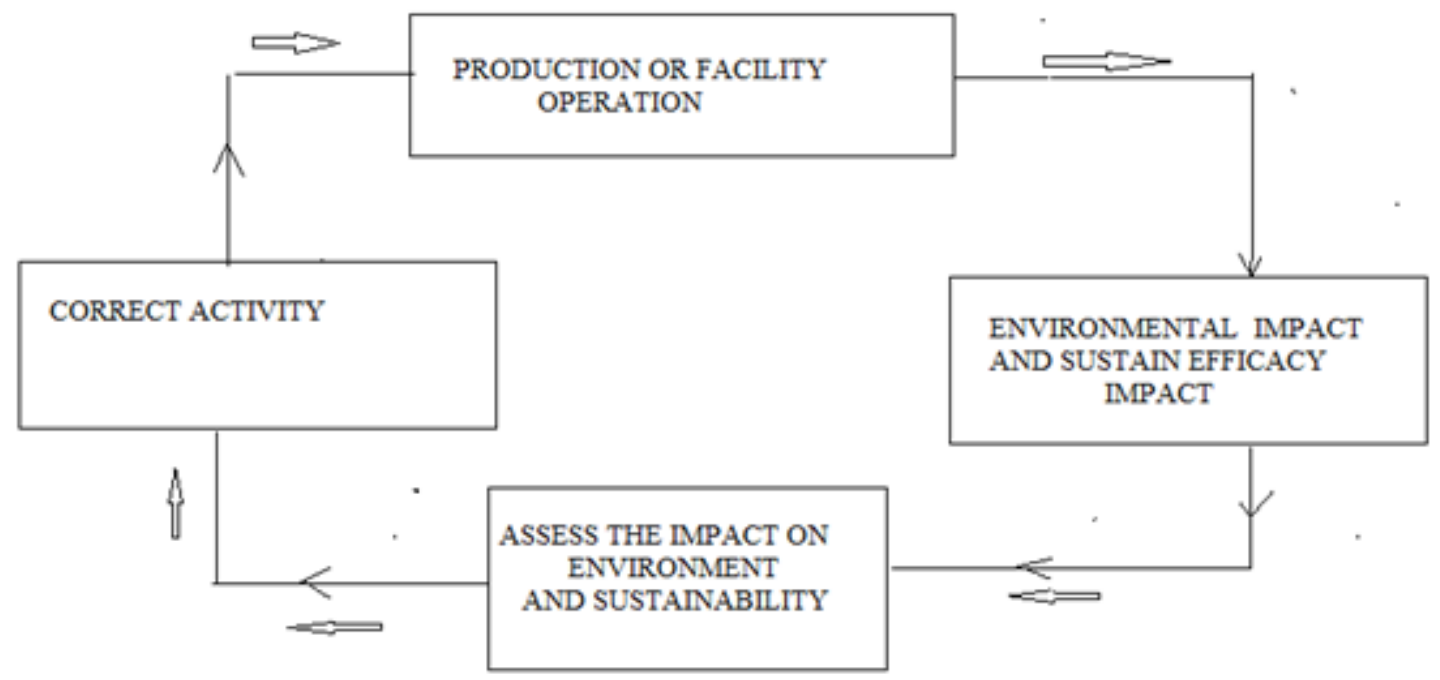

Figure 6. Environmental and sustainability efficacy entitled 'after-the-fact' evaluation

Project planning and decision-making should include the integrative consideration of engineering or technical, economic, environmental, ethical and social factors. A midget electrode project was taken as a case study for the SEA process (Figures 5 and 6). The international EIA process has been designed for the sustainable midget electrode project design and construction to identify and predict the potential effects on the physical, biological, ecological, socio-economic and cultural environment and on human health and well-being are adequately protected. Environmental impact statements have been prepared for the project by considering the environmental and socio-economic factors with respect to development and other proposed actions. Therefore, the EIA system is a potentially useful component of good environmental management [2]. 
In the chromium tanning industry, chromium environmental contamination and pollution is discharged beyond the safety limits, which seriously affects the life on earth (lyer, 2007). Toxic emissions from industries, thermal power plants, smelting pollution, auto exhaust pollution in large metropolitan areas and photochemical smog have been poisoning the atmosphere beyond the permissible levels, which has caused serious health hazards. Air pollution causes adverse environmental health and social impacts. Mindless disposal of untreated industrial wastes in Odisha chromite mines and other radio-active wastes in nuclear power plants, construction debris, sanitary wastes, hazardous wastes, municipal solid wastes (MSW), agricultural wastes and domestic wastes has contaminated and polluted the water, soil and land beyond the tolerable limits, which have adversely affected land fertility, water quality, vegetation, aquatic and marine life [6]. This is proving to be more and more hazardous as this development is continuously damaging the environment, viz. melting of glaciers, climate change, carbon tetra chloride emission, greenhouse gas emission and ozone layer depletion. For example, the continuous increase in $\mathrm{CO}_{2}$ concentration in the atmosphere and industrial emission of about $382 \mathrm{ppm}$ lead to climate change. This decrease in glaciers has contributed to about $29.5 \%$ of the mean sea level rise since 1991 . Water supplies stored in the glaciers have been projected to decline. In addition to contaminating and polluting air, water, soil and land, intensive technological activities also lead to the depletion of natural resources [6].

This is required to bring our energy and intellectual capacity in tandem whereby it can meet the challenges efficiently without major disruptions, as well as without compromising on the livelihood of future generations' needs. Development would have occurred without damages to the environment and major disruption, and the process of urbanisation and industrialisation would have occurred in a sustainable manner by utilising the resources efficiently. Now, these environmental problems are the present environmental challenges and opportunities for improvement. To overcome these environmental problems, new and more efficient solutions, technologies, processes and products alongside behavioural change are required.

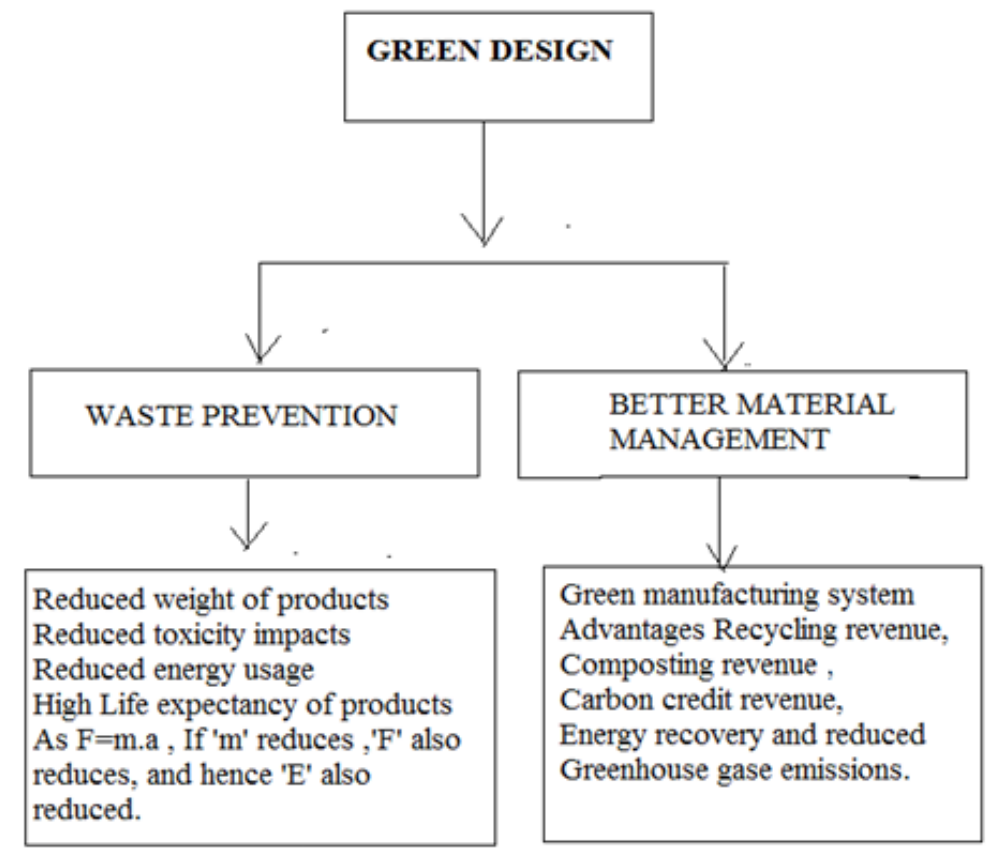

Figure 7. Dual goals of the green design and manufacturing process

Sustainable intelligent (Al) systems applied to low carbon and energy-efficient technology of industries can make contributions to mitigating the impacts of economic growth on global warming (Figure 7) (lyer, 2014). The resultant outputs of green products and services are environmental advantages with good performance and cheaper prices. The dual goals of green design are the waste 
prevention and better material management, as shown in Figure 7. The design and construction of green buildings have considerably reduced the environmental impacts associated with manufacturing, use and disposal [5].

Prior to the enactment of the NEPA on Environment in 1970 in the USA, only technical or engineering and economic factors dominated the planning and decision-making process in most of the world projects, plans, programmes, permits, policies and legislative actions. As per the sustainable intelligent systems research results, the project planning and decision-making process must include the integrated consideration of engineering or technical, economic, environmental, safety, ethical, social and sustainability factors. This important consideration can be referred to as the 'concept of the four Es and $1 \mathrm{~S}^{\prime}$ in organisational planning and decision-making process. There are ecological and biogeochemical principles and tools such as energy flows and material cycling, element ratios, mass and energy balance, element cycling and product environmental LCA (Figure 8) available in order to solve major environmental problems that we face in our world today, such as global warming, acid rain, environmental pollution and increasing greenhouse gases.

\subsection{Sustainable intelligent systems for product societal environmental LCA}

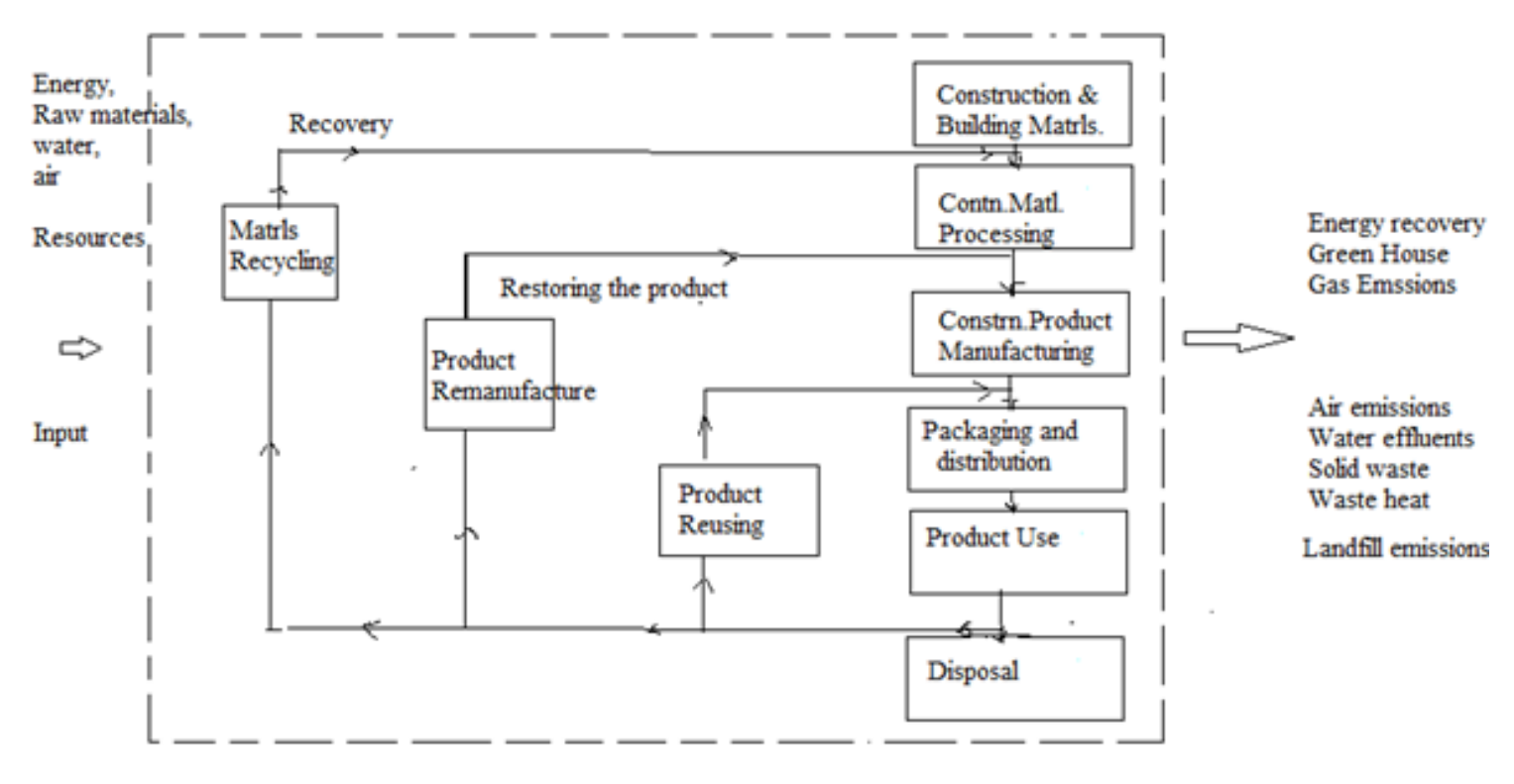

Figure - 8: Construction Product environmental lifecycle analysis (LCA)

Figure 8. Construction of the product environmental LCA

The engineering product environmental LCA is used for identifying and measuring the impact of industrial products on the environment and sustained efficacy by means of mass and energy balance methods (Figure 8) [4]. The LCA considers the activities related to the extraction of raw materials, ancillary materials, equipment production, use, disposal and ancillary equipment [2].

\subsection{EHIA Process for nuclear power plant project}

\subsubsection{Towards sustainable constructional development}

The EHIA process is proposed in this research for nuclear power plant projects during the construction phase in order to address psychological health impacts on workers and nearby residents [3]. The environmental health impact assessment can be defined as the systematic identification and evaluation of the potential environmental health impacts or effects of the proposed nuclear power 
projects, plans, programmes, policies or legislative actions relative to the physico-chemical, biological, cultural and socio-economic components of the total environment. At present, there are more than 437 nuclear power plants situated in the world. It may be worth mentioning that none of the nuclear power projects, plans, programmes, policies or legislative actions in the world has got sustainable practice in conduction of the EHIA process [3]. The nuclear power plants generate electricity while using heat generated in pressurised water reactors where nuclear reaction takes place. During the construction phase of nuclear power plants, uranium-235, thorium-232 and plutonium-239 are used as fuels in nuclear reactors causing nuclear fission. At that time, a copious amount of radiation dose due to the radioactive pollution escapes out in the order of about 120-240 billion Becquerel (120 $\mathrm{GBq}$ ), i.e., $50-100 \mathrm{~g}$ of radiation activities, viz. alpha $(\alpha)$, beta $(\beta)$ and gamma $(\gamma)$, as against the safe limits of $0.1 \mathrm{~Bq} / \mathrm{l}$ or $\mathrm{Bq} / \mathrm{kg}(\mathrm{ppm})$ in land, air and water, when operation, repair and maintenance of replacing old nuclear fuels with new fuels taken place. Exposure to high levels of radioactive pollution damages mental health and is a psychological burden on workers and nearby residents. As per the psychological health impact survey conducted by the author in a nuclear power plant at Quinson, China, severe psychological disorders including radioactive poisoning, depression and post-traumatic stress were investigated to an extent among $49 \%$ of the nearby residents in and around $82 \%$ of the nuclear power plants in the world (Iyer, 2004) (World Engineers' Convention, Shanghai, China 2004). Psychological health impact loadings due to radioactive environment on workers and nearby residents have been studied in this research during the test run phase using computer simulation models. The psychological health impact assessment on workers and nearby residents has been addressed to mitigate psychological health impact loadings on workers and nearby residents.

\subsection{EHIA process for sustainable industrial}

\subsubsection{Development using sustainable intelligent systems}

In this research, the EHIA process has been investigated in the cotton double roller (DR) ginning industries using chrome composite leather clad (CCLC) washers for the design and development of an eco-friendly alternative (lyer, 2007). The objective is to assess the environmental health impacts of the Indian cotton ginning industries. Most of the cotton ginning operations are performed by using DR ginning machines which play an important role in the Indian cotton ginning industries. The rollers used are made of CCLC covering fixed to a shaft. The CCLC contains of about $18,000-36,000 \mathrm{mg} / \mathrm{kg}(\mathrm{ppm})$ of chromium particles [42]. When the cotton seed is processed in the DR ginning machine, the lint cotton is contaminated with hexavalent chromium dust of about $140-1990 \mathrm{mg} / \mathrm{kg}$ (ppm) which is a carcinogenic substance against the safe limits of $0.1 \mathrm{ppm}$. During the cotton ginning process due to persistent rubbing of the CCLC over a stationary knife, the chromium particles are adsorbed into the lint cotton such that the spun yarns and woven fabrics get contaminated by about 100-200 ppm which according to World Health Organisation's eco-standards should not be more than $0.1 \mathrm{ppm}$. The CCLC rollers used in the cotton roller ginning machines get powdered during the ginning process. As chromium is a specific dust, gin and mill workers and residents are directly exposed to this carcinogenic substance and are vulnerable to environmental health hazards. To offset this problem, pollution-free eco-friendly washers/rollers for both laboratory and commercial studies have been fabricated and experimented. The environmental health inventory (EHI) serves as the basis for evaluating the potential environmental health impacts of both beneficial and adverse proposed actions. The environmental health impact statement describes the affected environmental health or environmental health setting without the project. The design and development of the $\mathrm{EHI}$ is an initial step in the EHIA process. It is concluded that EHIA process should be conducted for certain projects, plans, programmes, legislative actions, policies in the project planning and decision-making process.

\subsection{International EIA process}

The international EIA process is a potentially good environmental management system (EMS). International organisation for standardisation (ISO)'s 14000 and 9000 standards focus on EMS and 
quality management system (QMS) of all sorts of organisations apart from more than 19,500 published standards. The EMS and QMS have been separately featured in ISO. EMS standards apply to the management system concepts of an organisation's environmental issues and opportunities [8]. It defines the features of an EMS that need to be in place to ensure that the organisation identifies and focuses on improving areas where they have significant environmental impacts. This system can be integrated with ISO 9000 QMS standards to achieve excellence in quality as well as environmental obligations. The overall aim of the EMS is to provide protection to the environment and to prevent pollution to manufacture eco-friendly products and services. The EMS focuses on key drives of performance excellence in products and processes, as well as organisations that are focused on delivering values to the customers, internal operational processes and to staff's learning. Hence, this system approach to the environmental management shall achieve excellence in the overall performance of the organisation. In the present study, about two-thirds of construction waste was recoverable due to the conduction of intensive on-site training programmes on recycling and composting processes as against the conventional construction management practices which could recover the waste of only $10 \%-15 \%$ (lyer, 2014).

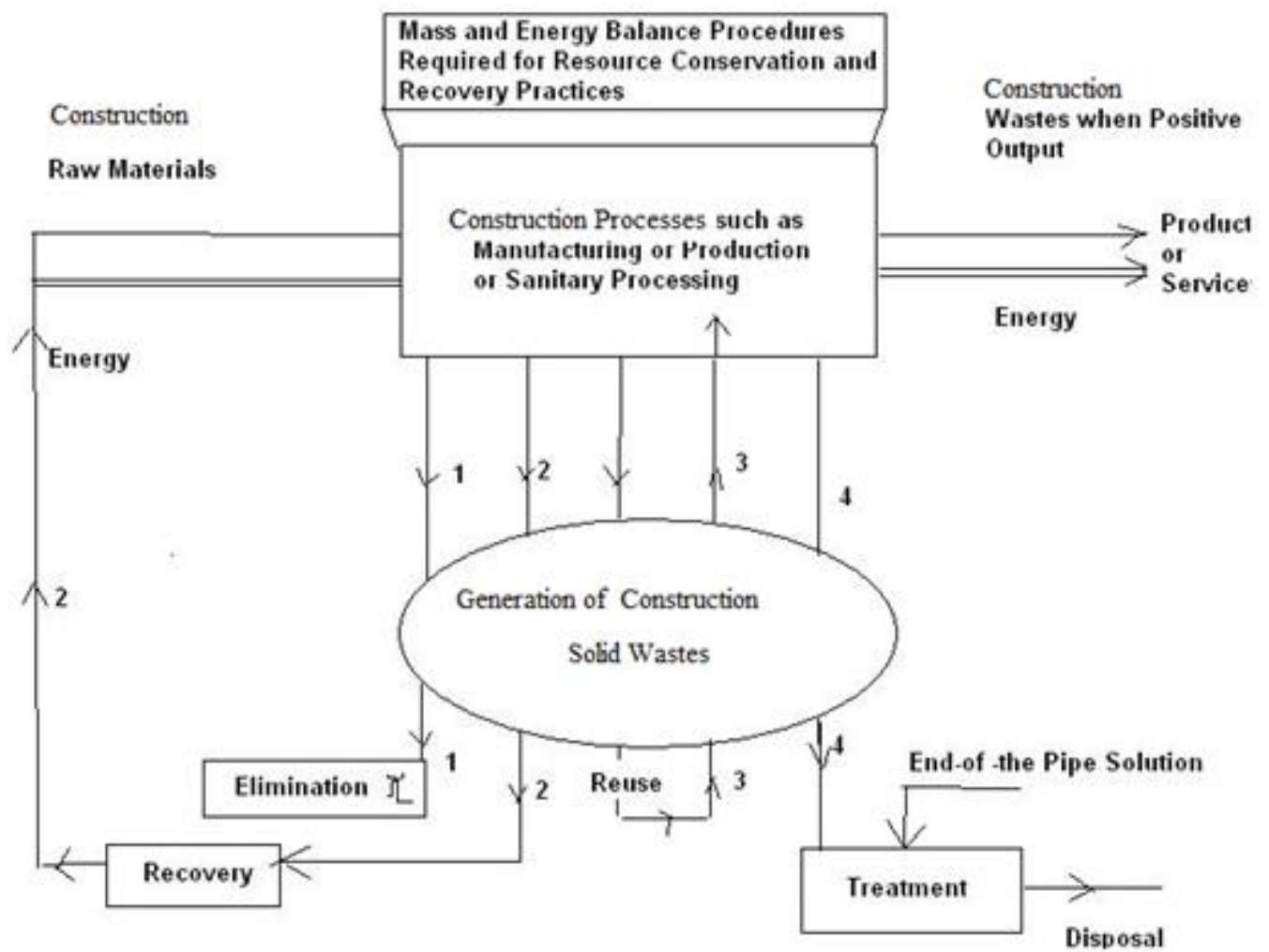

Figure 9. Schematic representation of the constructional process or activity showing sustainable construction of waste management

Construction wastes are produced by the construction sector. The study has been attempted to identify and evaluate special waste minimisation hierarchy of waste management for properly managing construction waste, including minimising generation and treatment that have been generated and disposing of waste residuals. A case study has been included on the generation of construction wastes and potential waste management strategies for a group or generic construction processes. All construction processes generate wastes in the form of liquids, solids or gases. Some wastes are considered as hazardous. The Al waste minimisation hierarchy of waste management is duly ranked from most desirable to least desirable (Figure 9). 1. Eliminating waste generation $=$ most desirable. 2 . Reducing waste generation $=$ most desirable. 3 . Reuse, recover or recycle waste materials 
= most desirable. 4. Treating waste to diminish quantity and to detoxify the hazardous and nonhazardous solid wastes $=$ least desirable. 5 . Disposing of waste residuals = least desirable. Waste minimisation includes only elimination, recovery, reduce, reuse and recycle hierarchies. Waste minimisation does not include treatment of wastes as well as disposal, which are points 4 and 5 , because these are traditional waste control strategies involving the treatment and disposal, which are called end-of-the pipe solutions and are costly affairs, as well as the control of high discharge standards. Modern waste control strategies involve points 1-3 which do not require end-of-pipe solution for the waste management problems. Solid and hazardous waste generation is the sum of material recovery and discard. Sustainable Intelligent systems' report on the waste audit conducted is presented for recovering two-thirds of MSW by recycling and composting processes (Figures10 and 11) (lyer, 2014).

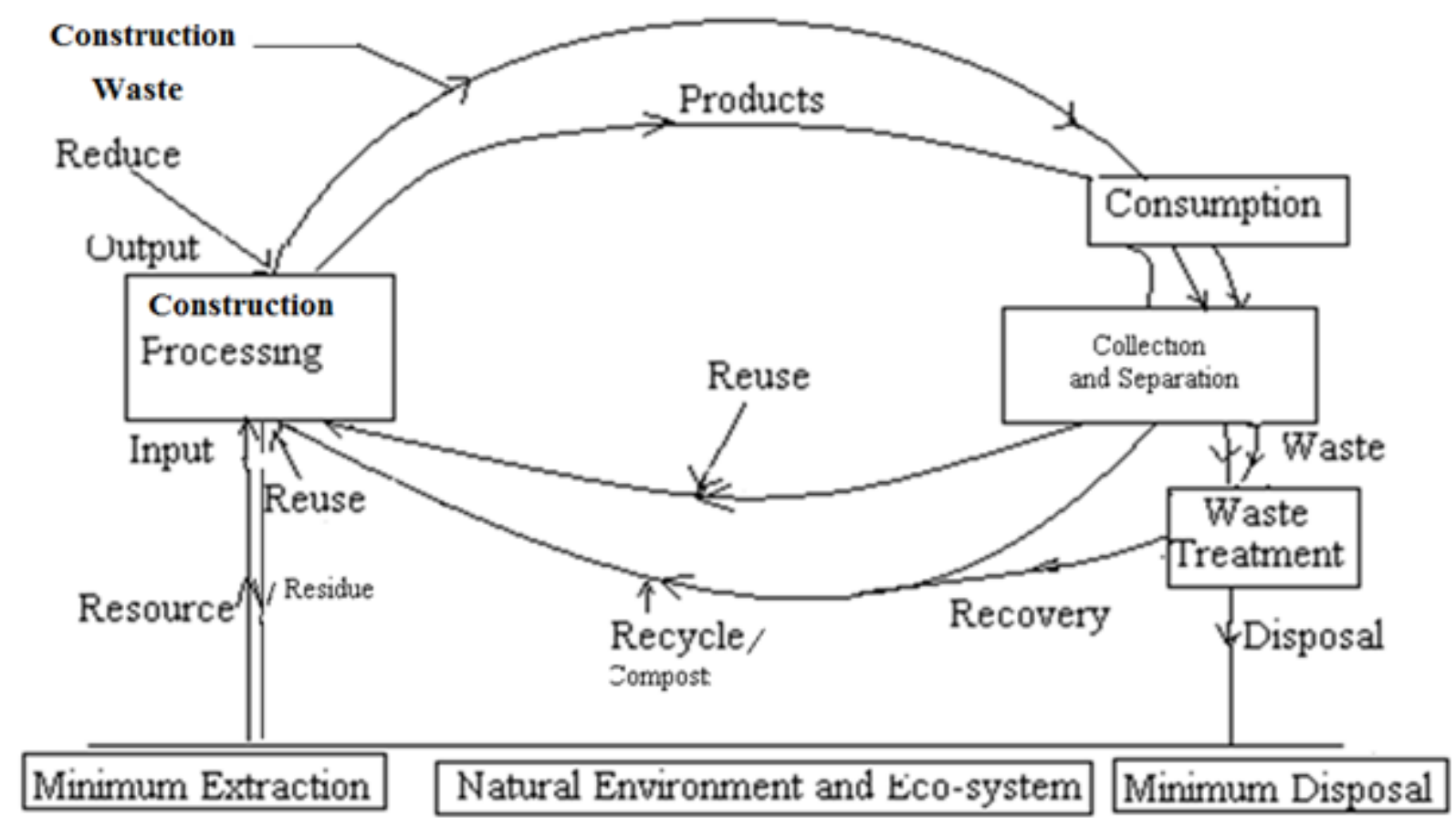

Figure 10. Closed loop-shaped green economy

To achieve sustainable economic improvement, natural resources should be utilised at optimum level to maximise efficiency as per the result analysis of optimum competitive and social markets applying sustainable intelligent systems. The efficiency of a kind of sustainable economic system is referred to as the 'AK' sustainable economic model, i.e., the product of engineering or technical factor level (A) and the capital (K). Sustainable economic improvement is explained by three factors which are given as follows:

- The natural increase in the accumulation of labour potential;

- Capital accumulation or money with which a business is started and run;

- Sustainable technological momentum can be referred as total factor productivity or efficiency in the construction process.

Such momentum keeps the capital development dynamic which emerges from the sustainable enterprise creation process, green products or services, new methods of production and processes, new construction management and transportation, new markets and new forms of constructional organisations. 


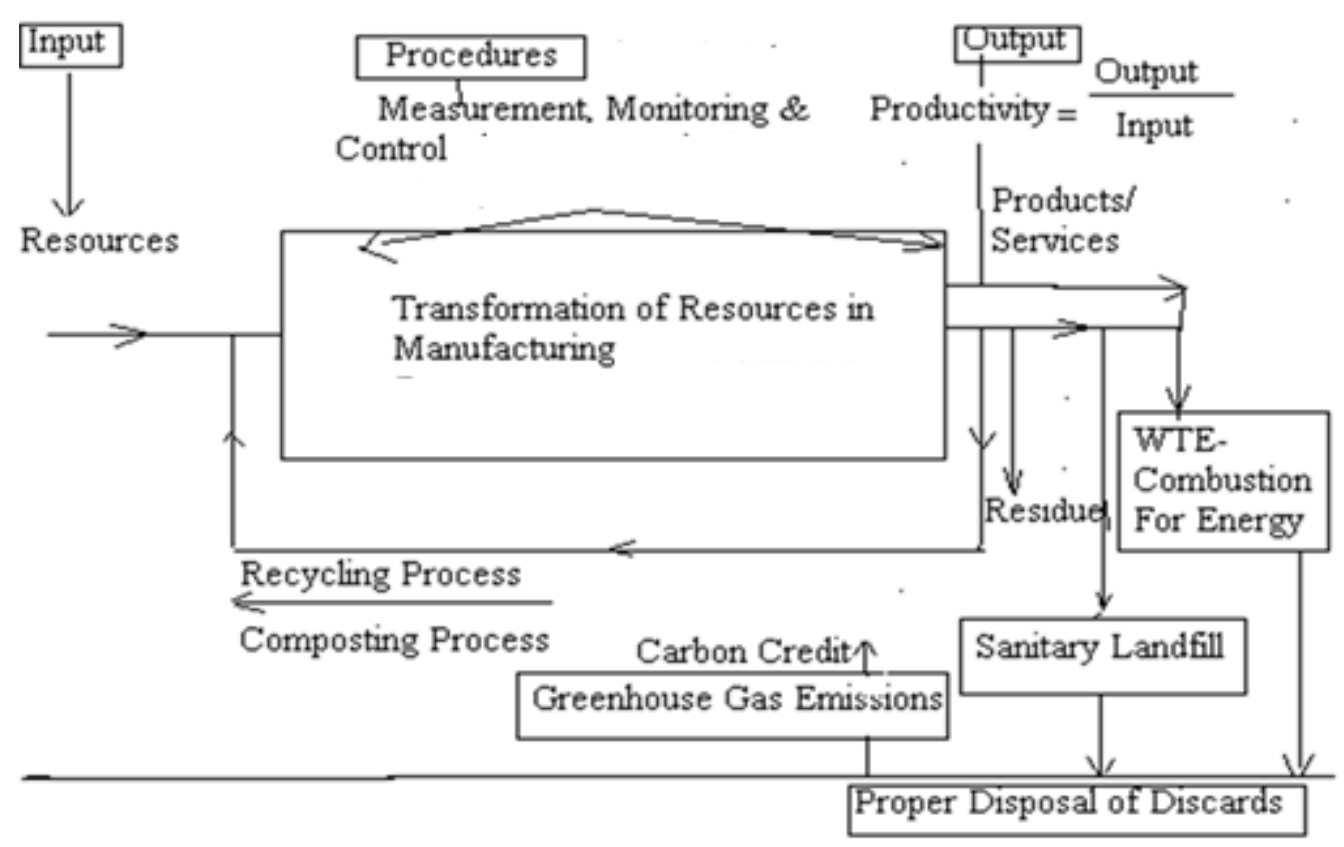

Figure 11. Sustainable AI management system

Standard production function (SPF) is expressed based on the operation approach as follows:

$$
Y=f(C, L)
$$

where $Y=$ output, $C=$ capital and $L=$ labour.

As knowledge is a crucial factor for economic growth, the SPF is modified based on the process approach as follows:

$$
Y=A . f\left(X_{1}, X_{2}, X_{3}, X_{4}, X_{5}, X_{6}\right)
$$

where ' $A$ ' represents the knowledge on sustainable constructional engineering or technical factor;

$$
Y=\text { output; }
$$

Input elements are manpower, machinery, materials, method, money and market denoted as $X_{1}, X_{2}$, $X_{3}, X_{4}, X_{5}, X_{6}$;

$$
f=\text { SPF. }
$$

As per the given SPF, knowledge is a decisive production variation and a sustainable innovation level is required in the engineering or technical system. The solution is the development of a reformed SEA implemented in the construction industries [5].

\subsection{Importance for the conduction of the EIA and management}

\subsubsection{Study of the constructional projects}

Historically, the choice of new constructional projects was primarily on one criterion, i.e., economic viability. Presently, second and third choice criteria, i.e., environmental and social impacts, have become a strong yardstick; therefore, a triple bottom line approach, i.e., economic, environmental and social factors, to constructional project viability can be applied sustainable intelligent systems. The EIA process is a systematic identification and evaluation of potential effects of proposed projects, plans, programmes, plans or legislative actions relative to the physico-chemical, biological, cultural and socio-economic components of the total environment. 
Iyer, G. V. (2020). Social impact assessment process for industry 4.0 to achieve sustainable artificial intelligence systems. Global Journal of Computer Sciences: Theory and Research. 10(2), 27-47. https://doi.org/10.18844/gjcs.v10i2.5393

\subsubsection{Steps to conduct EIA and management}

Step 1: Identification of the quantity and quality characteristics of the concerned environment of the proposed project.

Step 2: Preparation of the description of the existing environmental resource conditions.

Step 3: Procurement of relevant quantity and quality standards.

Step 4: Impact predictions.

Step 5: Assessment of impact significance.

Step 6: Identification and incorporation of mitigation measures.

\subsubsection{Conduction of the EIA study for efficient constructional industrial projects}

1. Prediction and assessment of impacts on the surface water environment.

2. Prediction and assessment of impacts on the soil and ground environment.

3. Prediction and assessment of impacts on the air environment.

4. Prediction and assessment of impacts on the noise environment.

5. Prediction and assessment of impacts on the biological environment.

6. Prediction and assessment of impacts on the visual environment.

7. Prediction and assessment of impacts on the socio-economic environment.

8. Prediction and assessment of impacts on the cultural environment.

9. Prediction and assessment of impacts on the archaeological environment.

10. Prediction and assessment of impacts on the anthropological environment.

\subsubsection{Sustainable intelligent systems applied in the EIA process that benefits the industries}

1. Considerable reduction in waste and depletion of resources.

2. Considerable reduction and/or elimination of the release of pollutants into the environment.

3. Green design and green building products to minimise their environmental impact on production, use and disposal.

4. Control of the environmental impacts on sources of raw material.

5. Waste minimisation and adverse environmental impact on new developments.

6. Promote environmental awareness among employees and the community.

\subsubsection{Sustainable intelligent systems for environmental management programmes}

- The organisation should establish and maintain a programme(s) for achieving the environmental objectives and targets. It should include designation of the responsible function, team or individual and a time frame for achievement as follows [8]:

1. State the objective/target.

2. State the purpose (how the objective/target will support the policy).

3. Describe how the objective/target will be achieved.

4. State the programme (team) leader.

5. Designate departments and individuals responsible for specific tasks.

6. Establish the schedule for completion of the tasks.

7. Establish the programme review, which will include format, content and review schedule.

\subsection{Sustainable intelligent systems for the conduction of the social impact assessment (SIA) study}

The SIA process is a systematic identification and evaluation of potential social effects of proposed projects, plans, programmes, plans or legislative actions relative to the society. The purpose of the SIA process is to bring about a sustainable and equitable biophysical and human environment (lyer, 2014). The SIA process includes monitoring, measurement and control opportunities including analysis and management of the intended and unintended social consequences whether both positive and negative impacts of planned interventions and any changes takes place in social transformation 
Iyer, G. V. (2020). Social impact assessment process for industry 4.0 to achieve sustainable artificial intelligence systems. Global Journal of Computer Sciences: Theory and Research. 10(2), 27-47. https://doi.org/10.18844/gjcs.v10i2.5393

process invoked by those interventions. The SIA process should include the analysis of the use of land, culture, industrial process, economic development and their impact on the service sectors such as water use, energy use, sanitation and traffic. The SIA process is carried out to ensure that there is no mismatch between the constructional development and sociocultural and socio-economic development of the project areas.

\subsection{Intelligent systems for the sustainable water and waste water quality management}

Water quality should be maintained so that water supply to consumers is safe and hygienic. Relevant water quality standards should be followed [9]. A sustainable sanitation facility is to be provided. The sanitation impact assessment study has been conducted for sanitation projects and plans. Sewerage system, storm water drainage systems, waste water treatment system, industrial waste treatment system and sustainable septic tanks are important on-site requirements. Relevant waste water discharge standards are to be followed. The process approach of a sustainable intelligent system for measurement, monitoring and control opportunities for water, waste water and industrial water quantity and quality should be followed [4].

\subsection{Sustainable intelligent systems for the safety engineering and management in industries (safety first)}

Sustainable Intelligent systems for safety management are used for the systematic identification and evaluation of potential safety requirements of proposed projects, plans, programmes, plans or legislative actions. The purpose of the Al safety engineering and management is to bring about designs and constructions of sustainable civil engineering structures. It has been observed that some construction methods and machineries used in India are obsolete and outdated because they are old and operate with poor performances in terms of productivity, quality, efficiency and safety. Some of the alternative machineries, which are indigenously manufactured, also do not guarantee for the superior performance and necessary safety conditions because of their poor design and materials of construction. It is mandatory to check for safety requirements about machineries, bridges, roads and buildings. Safety personnel responsible for overseeing the safety of all operating personnel must be cognisant of the latest laws and regulations pertaining to worker safety and occupational health [37]. These are changed and/or updated from time to time. Checking for safety ensures that the question of safety will not be overlooked; it is well to have all plans, specifications and drawings checked for safety, making special provision for this in each set of specifications and in the title plate of each drawing duly checking periodically for cranes, hoists, ventilation, lifts, tackles, fire protection systems, alarms, buildings, mechanical guarding and electrical and electronic equipment and heavy engineering equipment. Personal protective equipment and materials include garments, clothing, gloves, safety shoes, hard hats, safety glasses, shields, respirators, full aprons, safety belts, and other safety items used by individuals [37]. Such sustainable Al equipment is important for personal protection and for safety. It is the manager's and supervisor's responsibility to ensure that these are used. As far as occupational-disease prevention is concerned, those persons engaged in or working near operation are exposed to appreciable quantities of dusts, fumes or gas; so, it is important that adequate control measures must be adopted. Some major considerations involved in the application of effective control to industrial occupational disease are given. Some of the policies, practices and procedures to prevent exposure of personnel to unsafe materials are also provided. As far as the worker's compensation law is concerned, it must be enacted strictly in our country. The principle involved is that the worker injured or disabled in construction industries should be enabled, through proper medical treatment, to return to wage-earning capacity as promptly as possible, and while incapacitated, he should receive compensation in lieu of wages, regardless of the fault. The expense of medical treatment and compensation should properly be borne by the industry and become a part of the cost of its products. The laws generally provide that worker injured in the industry should be furnished with the necessary medical treatment and, in addition, compensation based on a percentage of their weekly wages, payable periodically. Dependents of employees killed in the industry are likewise compensated. The 
occupational diseases law provides provision for compensation benefits in occupational disease cases. The enactment of worker's compensation laws and occupational disease law should increase materially the cost of insurance to industry. The increased cost and the certainty with which it is applied will put a premium on accident prevention work. This cost can be materially reduced by the installation of safety devices [4]. Research experience has shown that approximately $80 \%$ of all the construction industrial accidents are preventable. As far as the fire loss prevention is concerned, it is an indispensable element in the construction industry. It exists only with top management direction and the support of labour. The designation fire protection usually encompasses the entire field of prevention of loss by fire, including both the causes for the occurrence of fires and methods for minimising their consequence. Some of the fire standards of protection to prevent injury and loss of life are given in this paper. Sustainable Intelligent systems in fire protection engineering practices both in building design and in safe operating practices are also included [38]. Construction noise safety is concerned; noise is recognised as a pollutant as both a nuisance and the cause of hearing impairment. There is evidence in construction sites that noise causes ailments such as hearing impairment and physiological and psychological disorders, including anxiety and heart disorders. Protection from noise is required when sound levels exceed those standards. When protective equipment is required, it must be provided by a trained person and periodic checks made of the effectiveness [38].

\subsection{Sustainable intelligent systems for the total quality management (TQM)}

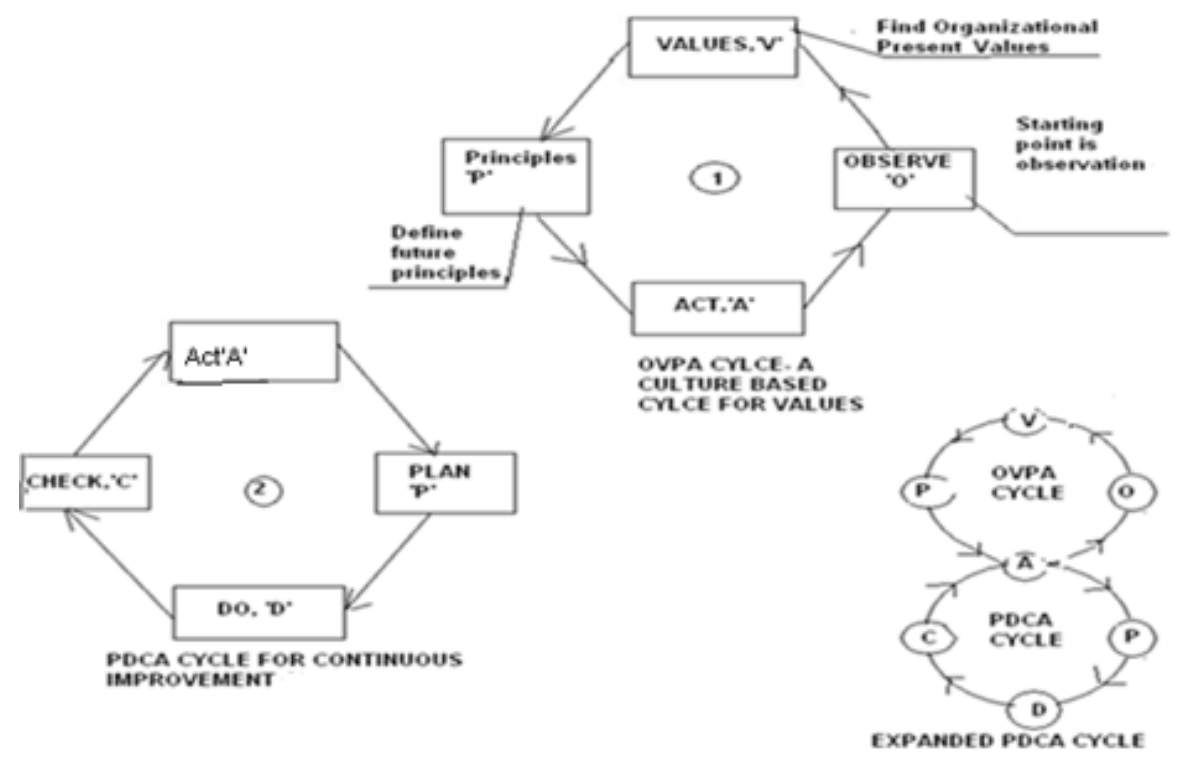

Figure 12. Conceptualisation of culture-based environmental and quality management entitled 'OVPA' cycle by incorporating the expanded PDCA cycle

Sustainable intelligent systems for TQM can be broadly defined as a set of systematic activities carried by an institution to efficiently achieve institutional objectives that satisfy beneficiaries at the appropriate time and price. The definition of quality is 'The totality of features and characteristics of products or services that bear on its ability, efficacy and values to satisfy a given or implied need'. TQM is a comprehensive and structured approach to an educational integrated management that seeks to improve the quality of educational services through ongoing refinements in response to continuous feedback. Thus, this standard definition of quality is applicable commonly to both products and services that are stated and unstated [8]. TQM has an important role to play in addressing quality issues surrounding the constructional development. TQM is a comprehensive and structured approach in the construction sector that seeks to improve the quality of services through ongoing refinements in response to continuous feedback. TQM leads to sustainable Al development. ISO 9000 series defines 
TQM as a management approach centred on quality, based on the participation of all its members and aimed at long-term success through customer satisfaction and benefits to all members of the organisation and society. Hence, TQM is based on quality management from the customer's point of view. TQM processes are divided into four sequential categories: plan, do, check and act (PDCA) (Figure 12). This is also called the PDCA cycle or Deming's cycle and sustainability cycle for continuous process improvement. In the planning phase, Al systems define the problem to be addressed, collect relevant data and ascertain the problem's root cause; in the doing phase, Al systems develop and implement a solution and decide upon a measurement to gauge its effectiveness and efficiency; in the checking phase, Al systems confirm the result through before-and-after data comparison; in the acting phase, Al systems document their results, inform others about process changes and make recommendations for the problem to be addresses in the next PDCA cycle and sustainability cycle. ISO 9000 series focuses on the quality management for all sorts of organisations. It has been proposed that the features of sustainable intelligent systems in QMS need to be in place to ensure, identify and focus on improving the areas where they have significant Al system deficiencies [4].

Sustainable intelligent systems for the ISO 14000 EMS standards apply to the management system to manage an organisation's environmental issues and opportunities [8]. It defines the features of an EMS that need to be in place to ensure that the organisation identifies and focuses on improving areas where they have significant environmental impacts. This system has been integrated with ISO 9000 QMS standards in order to achieve excellence in quality as well as environmental obligations in the midget electrode project. The overall aim of the EMS is to provide protection to the environment and to prevent pollution and manufacture eco-friendly products and services. The ISO 14000 series of standards assists the organisations to excel in environmental and economic gains for continuously improving organisational performances. They are used for the prevention of pollution, reduction of wastes, enhancement of internal management system efficiency, optimum utilisation of resources and compliances for legal and regulatory requirements. EMS can be basically divided into five events which form the sequence of a cycle (Figure 13). These five events are as follows: (1) environmental policy, (2) environmental planning, (3) environmental implementation and operations, (4) checking and corrective actions and (5) management review. The ISO 14000 series of standards has also been designed to cover the areas of socio-environmental issues and opportunities for the organisations to compete the global customer-centric markets so that the products and services can be manufactured at par with the international requirements [8].

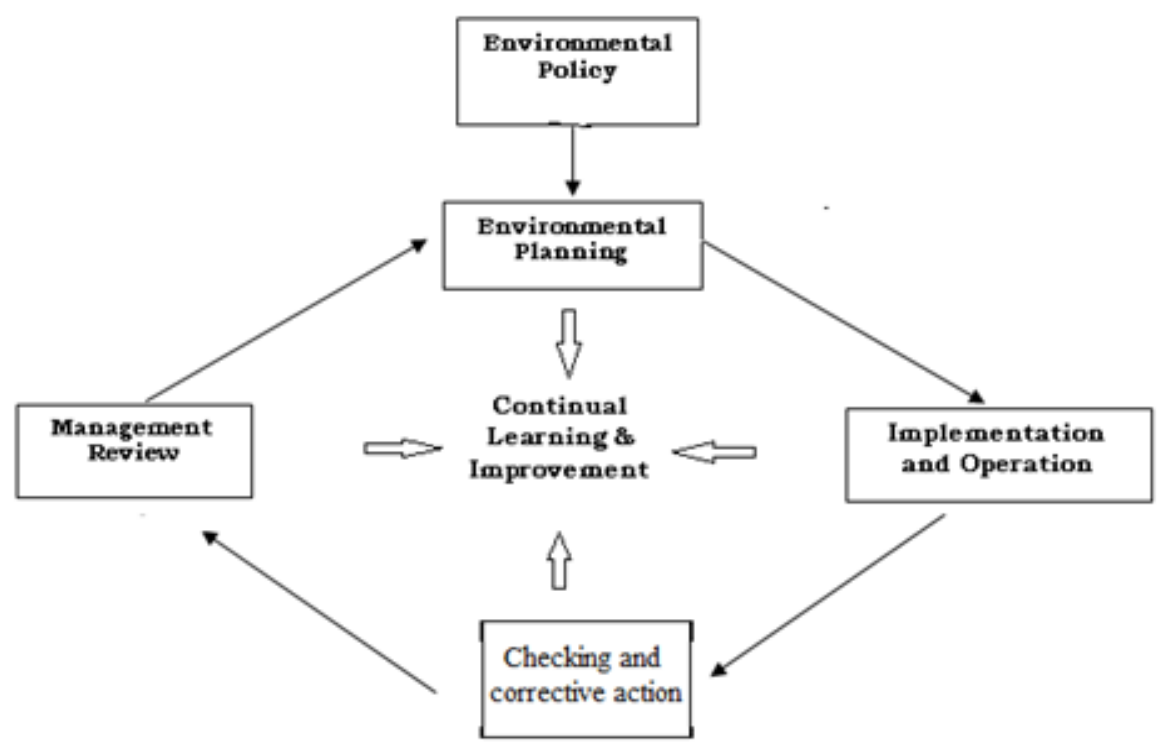

Figure 13. Environmental management system 
Sustainable intelligence systems in EMS focus on key drives of performance excellence in products and processes, as well as organisations, that are focused on delivering values to the customers, internal operational processes and to staff's learning. It may be mentioned that environment and quality management is a managerial approach centred on environment and quality through beneficiary satisfaction in construction industries that lead to economic improvement and sustainability [3]. Hence, this system approach to the socio-environmental management shall achieve excellence in the overall performances of the organisation.

\section{Conclusion and Recommendations}

The SEA process for sustainable intelligent systems has aimed to incorporate environmental and sustainability factors into the project and decision-making process, such as projects' formulation and appraisal of Indo-Matsushita midget electrode (battery carbon rod) plant in 1979 at Tada that included polices, programmes, plans and legislative actions. The primary purpose of the SEA process for sustainable intelligent systems is to encourage the consideration of the environment, safety, health, social and sustainability factors in the organisational PPD process and to arrive at actions that are compatible. The EIA should be considered as an official tool to protect the environment. The sanitation impact assessment has been investigated for sanitary projects and plans. The EIA process has a multidisciplinary approach that is necessary for providing the prevention mechanism for environmental management and protection in any constructional development. The EIA process is designed to identify and predict the potential effects on the physical, biological, ecological, socioeconomic and cultural environment and on human health and well-being are adequately protected.

As per sustainable intelligent systems research results, the PPD process should include the integrated consideration of technical or engineering, economic, environmental, safety, health, social and sustainability factors to achieve intelligence excellence. The SEA process for sustainable intelligent systems, which is a protocol, has been proposed for checking the quality of environmental and social assessments and management plans. This treaty and official government procedures of SEA was helpful in the decision-making process much earlier than the EIA process. Therefore, it is key tool for sustainable development. The SEA aims to incorporate environmental and sustainability considerations into strategic decision-making processes, to formulate policies, plans, programmes and legislative actions.

Prior to the NEPA process in 1970 in the USA, technical and economic factors dominance the world's projects. The objective of the study is to conceptualise the SEA process for sustainable intelligent systems based on 15 sustainable DPRs submitted by the extension learners of the DEBM (OLPE) course conducted by the EDI of India during the RY 1999-2019 under the author's counsellorship. Sustainable Intelligent systems for the ISO 14000 EMS standards apply to the management system concepts of TQM to the management of an organisation's environmental issues and opportunities. It defines the features of an EMS that need to be in place to ensure that organisations identify and focus on improving areas where they have significant socio-environmental impacts. EMS focuses on key drives of performance excellence in products and processes, as well as organisations, that are focused on delivering values to the customers, internal operational processes and to staff's learning. Hence, this sustainable intelligent system approach to the environmental management shall achieve excellence in the overall organisational performance. Engineering product socio-environmental LCA has been conducted using sustainable intelligent systems for identifying and measuring the impact of construction industrial products on the environment and sustain efficacy by means of mass and energy balance methods. LCA considers the activities related to raw materials, transformation, ancillary materials, equipment, methods, market, production, use, disposal and ancillary equipment. As far as the safety is concerned, sustainable intelligent systems have been applied for enforcement of PPEMs that include garments, clothing, gloves, safety shoes, hard hats, safety glasses, shields, respirators, full aprons, safety belts and other safety items used by individuals. Such equipment is important for personal protection and safety. It is the manager's and supervisor's 
responsibility to ensure that these are used. The enactment of worker's compensation laws and occupational disease law should increase materially the cost of insurance to the industry. The increased cost and the certainty with which it is applied will put a premium on accident prevention work. This cost can be materially reduced by the installation of safety devices in sustainable intelligent systems. Sustainable Intelligent system research experience has shown that approximately $80 \%$ of all the industrial accidents are preventable. It is concluded that sustainable intelligent systems coupled with quality management is a managerial approach centred on environment and quality through beneficiary satisfaction that leads to economic improvement and sustainability based on the triple bottom line approach. Sustainable Intelligent systems for TQM play an important role in addressing quality issues surrounding the sustainable development. Sustainable Intelligent systems for sustainable water and waste water management have been discussed. The SIA and EHIA processes were conducted for a nuclear power plant to consider the safety and health impacts to mitigate psychological health loadings on workers and nearby residents. The SEA system for sustainable intelligent systems is a potentially useful element of good socio-environmental management and sustainable development; however, as currently practiced in industries, it is far from perfection. Emphasis should be given in industries on maintaining economic viability of the operation, while in turn taking care to preserve the ecological and social sustainability of the country using sustainable intelligent systems. The international EIA process required a multidisciplinary approach that has been conducted at a very early stage of Indo-Matsushita carbon rod project in 1982 at Tada for economic, environmental and social viabilities. The paper highlights SEA process conducted for certain projects that based on operation and process approach and associated studies for sustainable development. As per research results, PPD process should include the integrated consideration of technical or engineering, economic, environmental, safety, health, social and sustainability factors to achieve business excellence. The SEA process protocol has been proposed for checking the quality of environmental and social assessments and management plans. This treaty and official government procedures of SEA were helpful in the decision-making process much earlier than the EIA process.

\section{Acknowledgement}

The author is thankful to the DIGP and Manager of CRPF-ITI, Avadi, Chennai-600065, for permission to publish this research work.

\section{References}

[1] L. W. Canter, Environmental Impact Assessment (McGraw-Hill International Editions), 2nd ed. New York, NY, USA: McGraw-Hill, 1996, p. 2.

[2] J. G. Hendry and G. W. Heinke, Environmental Science and Engineering, 2nd ed. New Delhi, India: PrenticeHall, 2002.

[3] I. V. Gurumurthy, "Environmental health impact assessment (EHIA) process towards environmental health for everyone all," in Proc. Abstr. Book 3rd World Conf. Health Sci. (HSCI). Kusadasi, Turkey: Pine Bay Holiday Resort Convention Center, Apr./May 2016, p. 88. [Online]. Available: http://www.h.sci.org and http://worldeducationcenter.edu,www.awer-center.org

[4] V. G. Iyer, "Strategic environmental assessment (SEA) process towards the sustainable design and construction of computer, communication, network engineering, machine learning and artificial intelligence systems," in Proc. Int. Conf. Educ., Manage., Econ., Hum. (ICEMEH), Shenzhen, China, Feb. 2019, pp. 380--396. [Online]. Available: http://www.emehconf.org and http://www.emehconf.org, doi: 10.12783/dtssehs/iceme2019/29618

[5] V. G. Iyer, "Sustainable enterprise creation process towards green economy," in Proc. 11th Biennial Conf. Entrepreneurship, vols. 1--2. Ahmedabad, India: Entrepreneurship Development Institute of India, Feb. 2015, pp. 1393--1405. 
Iyer, G. V. (2020). Social impact assessment process for industry 4.0 to achieve sustainable artificial intelligence systems. Global Journal of Computer Sciences: Theory and Research. 10(2), 27-47. https://doi.org/10.18844/gjcs.v10i2.5393

[6] V. G. Iyer, "Industrial landfill sources of air water and land pollution," World J. Environ. Res., vol. 1, no. 1, pp. 1--4, 2011.

[7] V. G. Iyer, "Properties of gin roller covering materials for cotton double roller gins (part-I)," J. Textile Assoc. (India), vol. 71, no. 2, pp. 59--61, Jul./Aug. 2010.

[8] C. C. Giri, D. K. Sharma, and S. Shukla, "Importance of the ISO 14000 in textile industry and its implementation framework," J. Textile Assoc., p. 5763, Jul./Aug. 2003.

[9] R. A. Wurb, Water Resources Engineering. Upper Saddle River, NJ, USA: Prentice-Hall, 2010.

[10] Metcalf \& Eddy, Inc., Wastewater Engineering Treatment Disposal Reuse. New York, NY, USA: McGraw-Hill, 2012.

[11] I. V. Gurumurthy, "Environmental and quality management for the higher education institutions to achive research and academic excellence," J. Mod. Educ. Rev., vol. 6, no. 2, pp. 135--146, 2015. [Online]. Available: http://www.academicstar.us

[12] I. V. Gurumurthy, "Social impact assessment process for an efficient socio-economic transformation towards poverty alleviation and sustainable development," Global J. Adv. Pure Appl. Sci., vol. 7, pp. 150-169, 2015.

[13] V. G. Iyer, "Strengthening of extension learning and education through sustainable entrepreneurship," J. Emerg. Trends Econ. Manage. Sci., vol. 6, no. 8, pp. 403--411, 2015.

[14] V. G. Iyer, "Social impact assessment (SIA) process for sustainable entrepreneurship," J. Emerg. Trends Econ. Manage. Sci., vol. 6, no. 7, pp. 207--219, 2015.

[15] V. G. Iyer, "Properties of gin roller covering materials for cotton double roller gins (part-II)," J. Textile Assoc., vol. 72, no. 2, pp. 79--84, Jul./Aug. 2011.

[16] V. G. Iyer, "Mixing of power plants for optimum utilization of energy resources," Indian J. Power River Valley Develop., vol. 57, nos. 1--2, pp. 73--88, Jan./Feb. 2007.

[17] V. G. Iyer, "Design and production of an eco-friendly technology for the processing of cotton fibers," J. Textile Assoc., vol. 67, no. 6, pp. 255--262, Mar./Apr. 2007.

[18] V. G. Iyer, "Eco-friendly rubberized cotton fabric roller development for cotton roller gins," J. Agricult. Saf. Health, vol. 13, no. 1, pp. 33--43, Jan. 2007.

[19] V. G. Iyer, "Environment and quality management for the higher education institutions to achieve research and academic excellence," in Proc. Souvenir 3rd World Summit Accreditation (WOSA) Theme Qual. Assurance Through Outcome Based Accreditation Organized Nat. Board Accreditation (NBA), Gurgaon, Haryana, Mar. 2016, pp. 325--337.

[20] V. G. Iyer, "Strengthening of extension learning and education through sustainable entrepreneurship," in Proc. 2nd Int. Conf. Nat. Capacity Building Strategy Sustain. Develop. Poverty Alleviation (NCBSSDPA), Manchester, U.K. Dubai, United Arab Emirates: NCBSLET, May 2015, pp. 308--316.

[21] V. G. Iyer, "Social impact assessment (SIA) process for sustainable entrepreneurship," in Proc. 2nd Int. Conf. Nat. Capacity Building Strategy Sustain. (NCBSSDPA), Manchester, U.K. Dubai, United Arab Emirates: NCBSLET, May 2015, pp. 266--278.

[22] V. G. Iyer, "Education coupled with entrepreneurial process approach towards sustainable development," Procedia Social Behav. Sci., vol. 177, pp. 147--161, Apr. 2015. [Online]. Available: http://www.sciencedirect.com/science/journal/18770428/177 and http://www.globalcenter.info/globeedu/wp-content/uploads/2013/06/GLOBE-EDU-2014-Abstracts-Book.pdf

[23] V. G. Iyer, "Unsafe chromium from cotton ginneries in ethiopia and development of a rubberized cotton fabric roller for cotton roller gins," in Proc. Nat. Symp. Sci., Technol. Innov. Nat. Develop. Nekemte, Ethiopia: Wollega Univ. Press, Mar. 2014, pp. 204--216. [Online]. Available: http://www.starjournal.org/wu-press.html

[24] V. G. Iyer, "Emerging trends in composites and advanced composites material technology," in Proc. 2nd Int. Conf. Adv. Mater. Process. Characterization (APMC), vol. 1. Chennai, India: Anna Univ., Feb. 2013, pp. 112-119. [Online]. Available: http://www.alliedpublishers.com 978-81-8424-820-3

[25] V. G. Iyer, "Environmental management system for the organizations to achieve business excellence," in Proc. 6th WSEAS Int. Conf. Syst. Theory Sci. Comput. (ISCGAV), Crete, Greece, Aug. 2006, pp. 220--232. 
Iyer, G. V. (2020). Social impact assessment process for industry 4.0 to achieve sustainable artificial intelligence systems. Global Journal of Computer Sciences: Theory and Research. 10(2), 27-47. https://doi.org/10.18844/gjcs.v10i2.5393

[26] V. G. Iyer, Properties of Covering Materials of Roller Used in Cotton Roller Gin: Unsafe Chromium Contamination and Pollution From Cotton Ginning Industries and Development of Eco-Friendly Alternatives, T. Melnic, Ed. Saarbr\"\{u\}cken, Germany: Lap Lambert Academic Publishing GmbH \\& Co., Jun. 2011.

[27] V. G. Iyer, Recent Research Results and Activities of Vijayan Gurumurthy lyer: Environmental Education and Research for Better Life, V. G Iyer, Ed. Saarbr\"\{u\}cken, Germany: Lap Lambert Academic Publishing, Jun. 2011.

[28] V. G. Iyer, "Policy study on solid waste minimization hierarchy for sustainable development," in Abstract Book of Ingenieria 2014-Argentina for the Subject Area: 4 Sustainability of Urban and Rural Territories (STUR). Buenos Aires, Argentina: Centro Cost Salguero, Nov. 2014. [Online]. Available: http://www.ingenieria2014.org/programa/chronogram

[29] V. G. Iyer, "Importance of waste audit process in a solid waste generating industry and its implementation framework," in Abstract Book of Ingenieria 2014-Argentina for the Subject Area: 1-1, Developing Economies (ECOs), Buenos Aires, Argentina, Nov. 2014. [Online]. Available: http://www.ingenieria2014.org/ programa/chronogram

[30] V. G. Iyer, "Study of efficient solid waste management for sustainable development," in Abstract Book of Ingenieria 2014 Latin America and Caribbean Congress and Exhibition-Argentina for the Subject Area: 2.2, Regional Integration of Infrastructures (RII). Buenos Aires, Argentina: Centro Cost Salguero, Nov. 2014. [Online]. Available: http://www.ingenieria2014.org/programa/chronogram.Paper

[31] V. G. Iyer, "Cost efficient integrated solid waste management approach practice in ethiopia, the case of implementation of intensive recycling program to the Addis Ababa bole international airport," in Abstract Book of Ingenieria 2014 Latin America and Caribbean Congress and Exhibition, Argentina for the of Subject area: 4.4 Sustainability of Urban and Rural Territories (STUR). Buenos Aires, Argentina: Centro Cost Salguero, Nov. 2014. [Online]. Available: http://www.ingenieria2014.org/programa/chronogram

[32] V. G. Iyer, "Study of sustainable enterprise creation process towards economic development," in Proc. Ingenieria Latin Amer. Caribbean Congr. Exhib., Argentina Subject Area, Developing Economies (ECO's). Buenos Aires, Argentina: Centro Cost Salguero, Nov. 2014. [Online]. Available: http://www.ingenieria2014.org/programa/chronogram

[33] V. G. Iyer, "Toxic tanning in leather tanneries without protection and occurrence of occupational accidents," in Proc. Abstract 28th Indian Eng. Congr. (IEC), Chennai, India, Dec. 2013, pp. 102--104.

[34] V. G. Iyer, "Some practical hints on occupational safety and health compliance requirements in industries," in Proc. Abstract Book Saf. Conf. Infrastruct. Sector. Chennai, India: Inst. Eng., Jul. 2013, p. 46.

[35] V. G. Iyer, "Design and development of disinfection polishing lagoons for effective reclamation and reuse of waste water," in Proc. Inst. Eng. World Congr. Urban Infrastruct. Developing Countries, VigyanBhawan. New Delhi, India: WFEO, Nov. 2007, Art. no. Theme-IV-19-26.

[36] P. M. Rapier and A. C. Klein, "Occupational safety and health," Tech. Rep., 1998.

[37] P. M. Rapier and A. C. Klein, "Fire protection," Tech. Rep., 1998.

[38] V. G. Iyer, "Strategic environmental assessment (SEA) process towards sustainable construction management development for the electrical, automation and mechanical engineering construction industries to achieve business excellence," in Proc. 3rd Int. Conf. Elect., Automat. Mech. Eng. (EAME) CDROM. Xi'an, China: Advances in Engineering Research, Jun. 2018, pp. 87--96. [Online]. Available: http://www.eame2018.org and https://www.atlantis-press.com/

[39] V. G. Iyer, "Study of reciprocal accountability and total quality management in education sector and its ideal implementation towards sustainable development," in Proc. Int. Conf. Comput. Modelling, Simulation Math. Statist. (AMMSA), vol. 143. Sanya, China: Atlantis Press, May 2018, pp. 402--411. [Online]. Available: http://www.ammsa2018.org/com.html and https://www.atlantis-press.com/proceedings/ammsa18/publishing https://www.atlantis-press.com/

[40] V. G. Iyer, "Total quality management (TQM) or continuous improvement system (CIS) in education sector and its implementation framework towards sustainable national development," in Proc. ASSEHR Int. Conf. Educ. Reforms Manage. Sci. (ERMS), Beijing, China, Apr. 2018, pp. 133--147. [Online]. Available: http://www.erms2018.org 
Iyer, G. V. (2020). Social impact assessment process for industry 4.0 to achieve sustainable artificial intelligence systems. Global Journal of Computer Sciences: Theory and Research. 10(2), 27-47. https://doi.org/10.18844/gjcs.v10i2.5393

[41] V. G. Iyer, "Total quality management (TQM) in education sector and its implementation framework towards sustainable international development," in Proc. Int. Conf. Comput. Sci., Electron. Commun. Eng. (CSECE), Wuhan, China, Feb. 2018, pp. 546--555. [Online]. Available: http://www.csece2018.org

[42] V. G. Iyer, "Environmental health impact assessment of chrome composite leather-clad rollers used by Indian cotton roller ginning industries and design and development of eco-friendly alternative," World J. Textile Eng. Technol., vol. 5, pp. 1--29, 2019. 